Article

\title{
Using an AHP-ISM Based Method to Study the Vulnerability Factors of Urban Rail Transit System
}

\author{
Liangliang Song ${ }^{1}$, Qiming $\mathrm{Li}^{1}{ }^{1}{ }^{*}$, George F. List ${ }^{2}$, Yongliang Deng ${ }^{3}$ and Ping $\mathrm{Lu}^{1,4}$ \\ 1 School of Civil Engineering, Southeast University, Nanjing 210096, China; 230129183@seu.edu.cn (L.S.); \\ 230159652@seu.edu.cn (P.L.) \\ 2 Department of Civil, Construction, \& Environmental Engineering, North Carolina State University, Raleigh, \\ NC 27695, USA; gflist@ncsu.edu \\ 3 School of Mechanics and Civil Engineering, China University of Mining and Technology, Xuzhou 221116, \\ China; dylcumt@cumt.edu.cn \\ 4 School of Civil Engineering, Lanzhou University of Technology, Lanzhou 730050, China \\ * Correspondence: 101001839@seu.edu.cn
}

Received: 12 May 2017; Accepted: 16 June 2017; Published: 20 June 2017

\begin{abstract}
As a sustainable means of public transportation, urban rail transit system undergoes rapid expansion in China. How to provide a safe and reliable service has been the subject of growing attention in this context. However, such work is challenging because rail transit systems are quite vulnerable and influenced by a set of interacting factors. Studying these vulnerability factors will contribute significantly to the operation of rail transit system. From this perspective, this paper made an exploration of the vulnerability factors based on an integrated method consisting of AHP (Analytical Hierarchy Process) and ISM (Interpretative Structural Modeling). Based on literature review, 21 vulnerability factors were identified. Subsequently, expert elicitation was employed to ascertain the importance of each factor and the interrelations among them. The results suggest that management and individual factors have the highest importance weights and the interrelations among vulnerability factors could be expressed as a five-layer structure, in which management factors were inclined to be at the lower level. The research provides valuable information for decision makers to take proactive strategies and reinforcement policies to guarantee safety operation of urban rail transit system and ensure urban public safety, which could promote the sustainable development of cities.
\end{abstract}

Keywords: urban rail transit; vulnerability factor; expert elicitation; analytical hierarchy process; interpretative structural modeling

\section{Introduction}

Many of today's developing cities are experiencing growing motorization, congestion, and worsening pollution, paralleling rail economic growth. China is no exception, especially with regard to its increasing rates of urbanization [1]. Urban rail transit, a sustainable transportation means with the merit of large capacity, high speed, and low pollution, has quickly become an ideal way to solve these problems. In order to realize urban sustainable development, the rail transit system is the inevitable choice for Chinese large- and medium-sized cities [1]. By the end of 2016, 30 cities from 17 provinces or municipalities nationwide have built rail transit systems with approximately 44 million passenger trips being made on a daily basis [2]. Meanwhile, 228 lines are still under construction simultaneously. There is no doubt that rail transit has evolved into the backbone of Chinese urban public transportation modes. In consideration of the number of rail transit systems, providing a safe and reliable service is bound to be an extremely crucial and rough challenge for the rail transit management departments. 
During last decades, plenty of works have been conducted to ensure and enhance the safety operation of the rail transit system. Kyriakidis et al. introduced the human performance railway index operation index (HuPeROI) for formulating mitigation strategies to minimize operators' degraded performance phenomena during the operation of rail transit system [3]. As the foundation of the HuPeROI, Kyriakidis et al. made a further research on the railway performance-shaping factors (R-PSFs) taxonomy, in which most common R-PSFS had been identified to improve safety management systems of railway organizations [4]. Song and Li carried out an empirical study on the relationship between the passenger density and the safety level of the station platform [5]. In contrast to many other public transport means, rail transit systems are more complicated, dynamic and open to the environment. Their operations are continuously affected by many factors, which make it vulnerable to disruptive events. Exploring the vulnerability of rail transit system has been proven to obtain significant contributions to improve systems' performance [6]. As a result, the vulnerability of rail transit system has gained extensive attention in regard to the influence of the network characteristics [7,8], the technology of the infrastructure and vehicles [9], the workers, and the passengers [10], just to mention a few. Nevertheless, what is noticeable is that almost all of these studies have been limited in that research on a portion of rail transit system. Few systematic explorations on the vulnerability have delved into a holistic analysis of the entire rail transit system [11,12]. For such reason, this research seeks to add to our understanding of the vulnerability of the entire system. It uses the analytical hierarchy process and interpretative structural modeling to perform a quantitative analysis of vulnerability factors so that management departments and decision makers can take reinforce measures to improve the system's ability to resist disruptive events and make the system safer.

The remaining sections of this paper are organized as follows. Section 2 elaborates on the definition of vulnerability and collects the vulnerability factors that significantly influence the safety operation of rail transit system based on literature review. An integrated methodology consisting of AHP (Analytical Hierarchy Process) and ISM (Interpretative Structural Modeling) is introduced in Section 3. Section 4 applies this method to identify the most important factors and demonstrate the interrelationships among the vulnerability factors. Based on the result from Section 4 , a further discussion about the findings is conducted in Section 5. Finally, Section 6 draws the overall conclusions.

\section{Vulnerability Factors of Rail Transit System}

The study of vulnerability has a long history, having been used to study power distribution systems [13], the Internet [14] and transportation systems [15] to just name a few. Because of differences between the various settings, vulnerability does not yet have a commonly accepted definition. However, two are closely related and relevant here. In the first, vulnerability means susceptibility to injury or attack [16]. In this sense, vulnerability is the manifestation of the inherent states of the system that express the extent of adverse effects caused by disruptive events that originate both within and outside the system boundary [17-21]. The second definition focuses on the fact that a system component or an aspect of a system can weaken or limit the system's ability to withstand a threat or to resume a new stable condition [22-24]. Given that the objective of this paper is to explore the global system vulnerability, the first definition is the one employed in this research. To a certain extent, this interpretation of vulnerability is similar concept of risk, which is seen as encompassing the estimation of probabilities of risk scenarios and associated negative consequences [19]. However, rather than assessing probabilities and consequences, the focus of analyzing vulnerability is to systematically explore the effects of failures for the purpose of identifying system weakness that may be vulnerable to exploitation by unknown or unimagined threats [20,25]. From this point of view, addressing the vulnerability factors of urban rail transit system involves answering the following question: what factors have the propensity to turn into the weaknesses that resulted in the failure of the system?

Collecting the vulnerability factors was a critical process of the research, which provided a foundation for the following analysis. Two typical options, literature review and expert interview, were employed to identify the vulnerability factors in this paper. Above all, peer reviewed studies that 
dealt with the safety operation of urban rail transit system were adopted to perform a comprehensive literature review, which resulted in an initial list of vulnerability factors. This list was then examined through the several interviews with five professors from Southeast University. All professors were knowledgeable in the field of safety with more than ten years of experience. After reviewing the preliminary list, the professors come to the consensus that all vulnerability factors derived from the existing literature were reasonable and of significance. Finally, a summary of 21 vulnerability factors are presented in Table 1, which could be grouped into six dimensions based on their properties and attributes: individual, equipment/facility, environment, management, structure, and emergency. Table 1 also provides an explanation of each factor and the related references.

Table 1. Vulnerability factors of rail transit system.

\begin{tabular}{|c|c|c|c|}
\hline Dimension & Factors & Explanation & References \\
\hline \multirow{5}{*}{$\begin{array}{l}\text { Individual } \\
\quad(\mathrm{B} 1)\end{array}$} & $\begin{array}{l}\text { Individual } \\
\text { technical capability } \\
\text { (C1) }\end{array}$ & $\begin{array}{l}\text { Technical capability depends on professional personnel } \\
\text { knowledge, skill, and experience. Experienced staff tend to } \\
\text { make fewer mistakes and are capable of dealing with and } \\
\text { solving unexpected problems. }\end{array}$ & {$[3,4]$} \\
\hline & $\begin{array}{l}\text { Individual security } \\
\text { awareness (C2) }\end{array}$ & $\begin{array}{l}\text { Security awareness is an individual's sensitivity to danger } \\
\text { and is correlated with alertness. It depends on the attention } \\
\text { devoted to sensing warnings and information regarding the } \\
\text { safety conditions. }\end{array}$ & {$[3,4]$} \\
\hline & $\begin{array}{c}\text { Individual } \\
\text { discipline (C3) }\end{array}$ & $\begin{array}{l}\text { Each staff member's positive attitude, healthy personality, } \\
\text { and sense of responsibility can make the system safer and } \\
\text { more efficient. }\end{array}$ & {$[26,27]$} \\
\hline & $\begin{array}{l}\text { Individual } \\
\text { workload and } \\
\text { stress }(\mathrm{C} 4)\end{array}$ & $\begin{array}{l}\text { Over workload and stress can cause loss of concentration, } \\
\text { unstable mood, and physical fatigue to subway staff, } \\
\text { especially when they are engaged in repetitive work. }\end{array}$ & {$[3,26,27]$} \\
\hline & $\begin{array}{l}\text { Individual physical } \\
\text { and physiological } \\
\text { state (C5) }\end{array}$ & $\begin{array}{l}\text { Staff that are in good physical and physiological condition } \\
\text { can keep a positive attitude toward work and achieve higher } \\
\text { performance. }\end{array}$ & {$[3,26,27]$} \\
\hline \multirow{3}{*}{$\begin{array}{l}\text { Equipment/ } \\
\text { facility (B2) }\end{array}$} & $\begin{array}{l}\text { Equipment/facility } \\
\text { condition (C6) }\end{array}$ & $\begin{array}{l}\text { The condition of equipment and facilities is affected by } \\
\text { service times and maintenance. Accidents are likely to occur } \\
\text { if the equipment and facilities are not in appropriate state. }\end{array}$ & {$[16,28]$} \\
\hline & $\begin{array}{l}\text { Equipment/facility } \\
\text { performance (C7) }\end{array}$ & $\begin{array}{l}\text { Equipment and facility performance depends on reliability } \\
\text { and the adoption of advanced technology and materials for } \\
\text { the system. }\end{array}$ & {$[16,28,29]$} \\
\hline & $\begin{array}{l}\text { Equipment/facility } \\
\text { protection }(\mathrm{C} 8)\end{array}$ & $\begin{array}{l}\text { The protection of the equipment and facilities can reduce the } \\
\text { impact of disruptive events to the system. For example, } \\
\text { installing platform screen doors can keep passengers from } \\
\text { falling onto the tracks or attempting suicide. }\end{array}$ & {$[16,28,29]$} \\
\hline \multirow{3}{*}{$\begin{array}{l}\text { Environment } \\
\text { (B3) }\end{array}$} & $\begin{array}{c}\text { Natural } \\
\text { environment (C9) }\end{array}$ & $\begin{array}{l}\text { Natural disasters, such as earthquakes, strong winds, and } \\
\text { snowstorms, can impair the safe operation of the system. }\end{array}$ & {$[16,29]$} \\
\hline & $\begin{array}{l}\text { Social environment } \\
\text { (C10) }\end{array}$ & $\begin{array}{l}\text { A subway system is especially vulnerable to terrorist threats } \\
\text { or attacks because it can be accessed easily by the general } \\
\text { public. A favorable social environment can limit such } \\
\text { events. }\end{array}$ & {$[16,29]$} \\
\hline & $\begin{array}{c}\text { Operating } \\
\text { environment }(\mathrm{C} 11)\end{array}$ & $\begin{array}{l}\text { The operating environment includes the travel conditions } \\
\text { for passengers and the working conditions for the staff. }\end{array}$ & {$[29,30]$} \\
\hline \multirow{2}{*}{$\begin{array}{l}\text { Management } \\
\text { (B4) }\end{array}$} & $\begin{array}{l}\text { Safety investment } \\
\text { (C12) }\end{array}$ & $\begin{array}{l}\text { Safety investment is the essential funding to ensure safe } \\
\text { operation of subway system, which could be in form of } \\
\text { introducing new technology, safety training, safety } \\
\text { incentives or other activities. }\end{array}$ & {$[26,28,30]$} \\
\hline & $\begin{array}{l}\text { Education and } \\
\text { training }(\mathrm{C} 13)\end{array}$ & $\begin{array}{l}\text { Staff can continuously improve their operational capability } \\
\text { by education and training, including technical training and } \\
\text { emergency drills. }\end{array}$ & {$[26,28,29]$} \\
\hline
\end{tabular}


Table 1. Cont.

\begin{tabular}{|c|c|c|c|}
\hline Dimension & Factors & Explanation & References \\
\hline & $\begin{array}{c}\text { Rules and } \\
\text { regulations (C14) }\end{array}$ & $\begin{array}{l}\text { Rules and regulations can make staff and departmental } \\
\text { responsibilities clear which contribute a lot to increase the } \\
\text { safety of operating the system. }\end{array}$ & {$[26,30]$} \\
\hline & $\begin{array}{l}\text { Organizational } \\
\text { structure }(\mathrm{C} 15)\end{array}$ & $\begin{array}{l}\text { Organizational structure defines how activities or tasks are } \\
\text { to be allocated, coordinated, and supervised to assist in safe } \\
\text { operation, which is particularly important to subway } \\
\text { systems for its direct impact on the communication and } \\
\text { cooperation between different departments. }\end{array}$ & {$[3,26,30]$} \\
\hline \multirow{3}{*}{ Structure (B5) } & Station layout (C16) & $\begin{array}{l}\text { Scientific station layouts can create a safe, convenient, and } \\
\text { comfortable environment for passengers. They can also } \\
\text { improve the efficiency of mustering and evacuating, which } \\
\text { exert the positive influence on mitigating the consequences } \\
\text { of disruptive events. }\end{array}$ & {$[30]$} \\
\hline & $\begin{array}{l}\text { Network topology } \\
\quad(\mathrm{C} 17)\end{array}$ & $\begin{array}{l}\text { The consequences of an accident can spread through a } \\
\text { network. For instance, the loss of a single node or link can } \\
\text { paralyze the whole network. The topology of the network } \\
\text { affects the rate at which these consequences spread, what } \\
\text { portions of the system they affect, and the extent of the } \\
\text { impacts. }\end{array}$ & {$[16,31,32]$} \\
\hline & $\begin{array}{l}\text { Equipment/facility } \\
\text { interdependency } \\
\text { (C18) }\end{array}$ & $\begin{array}{l}\text { Equipment/facility interdependency is a relationship } \\
\text { between two subsystems by which the state of each } \\
\text { subsystem influences or is correlated to the state of the other. } \\
\text { Such interdependencies can exacerbate the system's } \\
\text { vulnerability and further aggravate the impact of accidents. }\end{array}$ & {$[16,33]$} \\
\hline \multirow{3}{*}{$\begin{array}{l}\text { Emergency } \\
\quad(\mathrm{B} 6)\end{array}$} & $\begin{array}{l}\text { Emergency } \\
\text { management plan } \\
(\mathrm{C} 19)\end{array}$ & $\begin{array}{l}\text { An emergency management plan is a course of action } \\
\text { developed to mitigate the damage of potential events that } \\
\text { could endanger the system's ability to function. }\end{array}$ & {$[29,30]$} \\
\hline & $\begin{array}{l}\text { Emergency } \\
\text { response execution } \\
(\mathrm{C} 20)\end{array}$ & $\begin{array}{l}\text { Accurate action taken in the initial minutes of an incident } \\
\text { can help control the incident and minimize the damage to } \\
\text { the system. The more efficient and timely the actions, the } \\
\text { less will be the impact of the accident. }\end{array}$ & {$[29,30]$} \\
\hline & $\begin{array}{l}\text { Emergency support } \\
\text { system setup (C21) }\end{array}$ & $\begin{array}{l}\text { Well-designed, well-equipped and maintained systems that } \\
\text { are used in emergencies can have a significant impact on } \\
\text { impact mitigation. }\end{array}$ & {$[29,30]$} \\
\hline
\end{tabular}

\section{Research Methodology}

The methodology used in the present study to better understand the 21 vulnerability factors was an integrated approach that consisted of the Analytical Hierarchy Process (AHP) and Interpretative Structural Modeling (ISM). The AHP was used to assign weights to each vulnerability factor and evaluate the relative importance of each factor properly, while the ISM was employed to intuitively describe the interrelationships among these factors. Although both techniques are more than three decade old, their merits of flexibility and robustness make them have extensive applications in many domains [34,35].

\subsection{Analytical Hierarchy Process (AHP)}

AHP, developed by Saaty [36], is widely used to make efficient and effective decisions for decision making problems that involve multiple objectives. It helps the analyst identify the key factors, determine the allocation of resources, and consider different preferences. By using AHP, decisions can be made using weights that based on subjective pairwise relative comparisons through multilevel hierarchic structures. AHP is a systematic and comprehensive method to solve multi-criteria decision problems and avoid inconsistencies in the decision-making process. The use of the AHP is illustrated below. 
Step 1: Model the decision problem as a hierarchy. The first step in AHP is to break down the decision problem into component factors and structure these factors in a hierarchical order from the broadest perspective to the most narrow (top to bottom, respectively).

Step 2: Construct pairwise comparison matrices. Once the hierarchy structure has been built, a series of pairwise comparison are performed for the production of the relative importance value of each factor by comparing it with other factor in the same level regarding their impact on an element above them in the hierarchy. The comparison is made by assigning numerical values to express the strength of the preference of one factor over the other, as shown in Table 2. Overall comparison questions are formulated as: (1) "What is the relative importance of factors in selecting the most preferred alternative?" (2) "What is the relative preference of alternative with respect to each factor?"

Table 2. Scale of preference between two parameters in AHP.

\begin{tabular}{|c|c|c|}
\hline $\begin{array}{l}\text { Intensity of } \\
\text { Importance }\end{array}$ & Definition & Explanation \\
\hline 1 & Equally & Two factors contribute equally to the objective \\
\hline 3 & Moderately & Experience and judgment slightly favor one factor over the other \\
\hline 5 & Strongly & Experience and judgment strongly favor one activity over the other \\
\hline 7 & Very strongly & Experience and judgment very strongly favor one over the other \\
\hline 9 & Extremely & The evidence favoring one over another is of the highest possible order of affirmation \\
\hline $2,4,6,8$ & Intermediately & Used to represent compromises between the preferences in weights $1,3,5,7$ and 9 \\
\hline Reciprocals & Opposites & Used for inverse comparison \\
\hline
\end{tabular}

Step 3: Examine the consistency of the hierarchy. After establishing pairwise matrices, the priorities of each factor in terms of its contribution to the objective are calculated through eigenvalues and eigenvectors of each pairwise comparison matrix. Specifically, the priorities of each factor are obtained from any pairwise comparison matrix $A$ as the solution of the following equation system,

$$
A \omega=\lambda_{\max } \omega, \sum_{i=1}^{n} \omega_{i}=1
$$

where $n$ is the size of the matrix according to the number of pairwise comparison, $A$ is the positive pairwise comparison matrix of order $n, \lambda_{\max }$ is the principal eigenvalue of $A$, and $\omega$ is the priority vector.

The consistency ratio $(C R)$ gives a measure of where the judgments in the pairwise comparison matrix lie (between totally consistent and totally random). It is obtained as follows:

$$
C R=\frac{C I}{R I}
$$

where $C I=\left(\lambda_{\max }-n\right) /(n-1)$ is the consistency index, and $R I$ is the average random consistency index for different matrix order, as shown in Table 3.

Table 3. Random consistency index value (RI).

\begin{tabular}{ccccccccccc}
\hline $\boldsymbol{N}$ & $\mathbf{1}$ & $\mathbf{2}$ & $\mathbf{3}$ & $\mathbf{4}$ & $\mathbf{5}$ & $\mathbf{6}$ & $\mathbf{7}$ & $\mathbf{8}$ & $\mathbf{9}$ & $\mathbf{1 0}$ \\
\hline $\boldsymbol{R I}$ & 0 & 0 & 0.525 & 0.882 & 1.115 & 1.252 & 1.341 & 1.404 & 1.452 & 1.484 \\
\hline
\end{tabular}

When the CR is less than 0.1 , the matrix is considered to be consistent. If the $C R$ is greater than 0.1 , the comparison matrix is considered inconsistent and it needs to be revised.

Step 4: Compute the weight of each factor. The priorities obtained from the comparisons are used to weight the priorities in the level immediately below for every factor. The process continues until the normalized principal eigenvectors, which give the weights for each factor, are obtained. 


\subsection{Interpretative Structural Modeling (ISM)}

Interpretative structural modeling (ISM), developed by Warfield [37], is a methodology of systemic structural modeling, which has been widely applied in identifying and summarizing relationships among factors. It is an interactive learning process in which a set of unique, interrelated variables are structured into a comprehensive systemic model presented as a hierarchy graph. ISM provides a means by which people can synthesize an objective hierarchy of the factors by mathematical deduction, given the pairwise relations among the factors. The general process of ISM development is described below.

Step 1: Identify the system factors set. A set of variables affecting the system is defined. The relevant parameters to be considered in analysis are generated by brainstorming and using a literature review, interviews, or other research tools.

Step 2: Construct the adjacency matrix. Depending on the situation and the factors, a contextual relationship is chosen from the following options: "depends on", "leads to", "impacts", "increases", and "decreases". When judging the relationship between any two factors, a direct binary relationship, $a_{i j}$, is formed by the following four principles:

(1) For the relationship $a_{i j}$, if $i$ has an impact on $j, a_{i j}=1$; if not, $a_{i j}=0$ and vice versa;

(2) If the two factors do not impact each other, then $a_{i j}=a_{j i}=0$;

(3) If the two factors impact each other, then $a_{i j}=a_{j i}=1$;

(4) When $i=j$, then $a_{i j}=a_{j i}=0$.

The adjacency matrix $A$ is generated from the total of the direct binary relationships.

Step 3: Generate the reachability matrix. According to the transition law characteristics, the reachability matrix $M$ can be calculated by the formula:

$$
(A+I) \neq(A+I)^{2} \neq \cdots \neq(A+I)^{r}=(A+I)^{r+1}=M
$$

The matrix multiplications satisfy Boolean algebra algorithms, where $I$ is the unit matrix. The power, $r$, in the equation, is defined as less than or equal to the number of the factors.

The reachability matrix is obtained by an algorithm-based process. Specifically, $(A+I)$ is multiplied by itself according to Boolean algebraic algorithms, until a power of the product reaches the identical matrix.

Step 4: Partition the reachability matrix into different levels. The reachability set $(R)$ and the antecedent set $(A)$ are derived from the final reachability matrix. The reachability set consists of the factor itself and other factors that it may impact, whereas the antecedent set consists of the factor itself and the other factors that may impact it. The intersection of these sets, $R \cap A$, is derived for all the factors. If $R \cap A=R$, the factor in $R$ will be located in the top layer and removed from consideration. This process is repeated to obtain the factors for the next level and then it is repeated iteratively until all the factors have been partitioned into the hierarchical levels.

Step 5: Draw a directed graph. A digraph is drawn to illustrate the hierarchical relationships among these factors in terms of nodes and lines of edges. The top-level factor is positioned at the top of the hierarchy and the second level factor is placed just below the top level. This process is repeated until the bottom level factors are placed at the lowest position in the hierarchy. A line is drawn if there is a direct link between the two factors, and a final graph is developed after checking all the relationships.

\subsection{The Integrated Methodology}

From the description of the AHP and ISM method, it is acknowledged that both techniques do not require any training stage and there are non-existent data for them. Generally speaking, under such circumstance, expert elicitation is regarded as the best option allowing for the production of primary data to conduct further analysis [38]. As a structured process that collects scientific and technical judgments from experts [39], expert elicitation is proven to be competent under the situation 
when other empirical data are expensive, limited or unreliable [38], and has been applied in many studies [40,41]. The expert elicitation adopted in this study could be decomposed into three steps. In the first step of the expert elicitation, all experts was independently provided with the background and required to make judgments on the relative weights of the factors as well as the relationships among the factors by means of one-to-one, face-to-face, in-depth interviews. The initial results ascertained were examined to make it accurate and reasonable in the second step. The third step consisted of several rounds of discussion on the initial results among experts, in which any disagreements were resolved until a consensus of opinion was reached.

A flowchart of the integrated methodology combining the AHP method and the ISM process adopted here is presented in Figure 1. First, a list of all possible factors is generated by a literature review and preliminary interviews. Then, the expert elicitation is employed to collect the data of this study. Ultimately, after reviewing and checking the intermediate outputs from the expert elicitation, the final result is obtained.

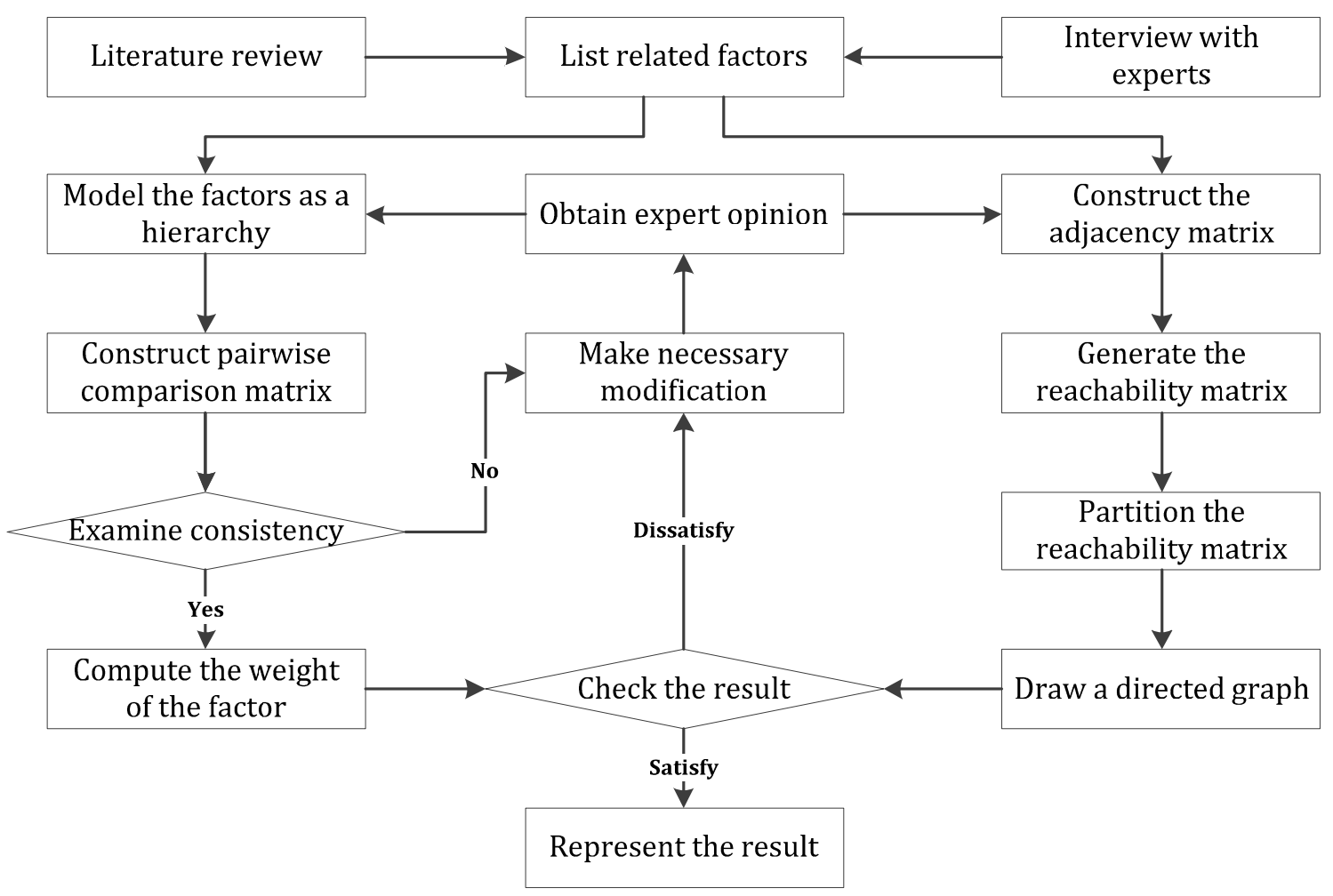

Figure 1. Flowchart of the methodology.

\section{Results}

In advance of utilizing the integrated methodology to analyze the 21 vulnerability factors, the expert elicitation was accomplished during late August 2016 and early December 2016. A panel of nine experts was invited to participate in making the judgments among vulnerability factors, consisting of five professors from Southeast University and four senior managers in Nanjing Metro Co., Ltd. (Nanjing, China). These experts all had more than 10 years of work experience, which could make the judgments more credible and reliable. Before making the judgments, several experts were consulted to make certain that the questions were properly phrased and established. As a result, seven rounds of discussion were carried out to reach an agreement, among which three discussions were on the importance of the factors and other four discussions were about the interrelations, respectively.

With respect to the AHP analysis, a three-level hierarchy structure of the vulnerability factors illustrated in Table 1 was developed. Unlike the conventional structure in most AHP models, the 
current structure used the goal of identifying the most contributing vulnerability factor on the first level. Six dimensions including individual (B1), equipment/facility (B2), environment (B3), management (B4), structure (B5) and emergency (B6) were placed at the criteria level. The sub-criteria level was composed of vulnerability factors (C1-C21). There was no alternative at the bottom. A pairwise comparison of the factors was conducted using the standard 1-9 scale given in Table 2 based on the question that with respect to a given dimension, and bearing in mind the overall goal of enhancing the safety of urban rail transit system, which of two factors can make the greatest contribution to the parent dimension? For the importance value of each pair factors, it equaled to the nearest integer of the geometric mean values which considered all experts' judgments. Finally, an assigned and normalized weight of each factor was obtained as shown in Table 4 . These weights indicate the importance of the factor itself. From the second row of Table 4, it is evident that management dimension ranks first in the criteria level, with an evaluation of 0.31203 . With an evaluation of 0.30552 , individuals dimension rank second, followed by emergencies dimension accompanied with an evaluation of 0.16408 . There is a slight gap between management and individuals. In contrast, the gap between individuals and emergencies is more obvious. The weights for the remaining elements are 0.09710 (structure dimension), 0.08204 (equipment/facility dimension) and 0.03924 (environment dimension). In addition, the ranks of the 21 vulnerability influencing factors in the sub-criteria level are shown in the last column of Table 4. The four most important factors are: "Education and training" (C13) and "Safety investment" (C12), and "Individual technical capability" (C1) and "Individual security awareness" (C2). The weight differences between the factors are less pronounced than the differences between the dimensions. As for the consistency of all judgments, relevant calculations were displayed in column 8 and 9 of Table 4. Apparently, all of the CR values are less than 0.1 , which indicates that the comparison matrices are of good consistency.

Table 4. The importance weights of all factors.

\begin{tabular}{|c|c|c|c|c|c|c|c|c|c|c|}
\hline \multirow{2}{*}{ Factor } & B1 & B2 & B3 & B4 & B5 & B6 & \multirow{2}{*}{ CI } & \multirow{2}{*}{ CR } & \multirow{2}{*}{ Weight } & \multirow{2}{*}{ Rank } \\
\hline & 0.30552 & 0.08204 & 0.03924 & 0.31203 & 0.09710 & 0.16408 & & & & \\
\hline $\mathrm{C} 1$ & 0.33493 & & & & & & \multirow{5}{*}{0.00347} & \multirow{5}{*}{0.00311} & 0.1023 & 3 \\
\hline $\mathrm{C} 2$ & 0.32337 & & & & & & & & 0.0989 & 4 \\
\hline $\mathrm{C} 3$ & 0.10572 & & & & & & & & 0.0323 & 11 \\
\hline $\mathrm{C} 4$ & 0.05797 & & & & & & & & 0.0177 & 18 \\
\hline C5 & 0.17801 & & & & & & & & 0.0544 & 7 \\
\hline C6 & & 0.59537 & & & & & \multirow{3}{*}{0.00279} & \multirow{3}{*}{0.00532} & 0.0488 & 9 \\
\hline $\mathrm{C} 7$ & & 0.12828 & & & & & & & 0.0105 & 20 \\
\hline $\mathrm{C} 8$ & & 0.27635 & & & & & & & 0.0227 & 15 \\
\hline C9 & & & 0.16341 & & & & \multirow{3}{*}{0.00449} & \multirow{3}{*}{0.00885} & 0.0064 & 21 \\
\hline C10 & & & 0.29696 & & & & & & 0.0117 & 19 \\
\hline C11 & & & 0.53963 & & & & & & 0.0212 & 16 \\
\hline C12 & & & & 0.35767 & & & \multirow{4}{*}{0.00122} & \multirow{4}{*}{0.00233} & 0.1116 & 2 \\
\hline C13 & & & & 0.37881 & & & & & 0.1182 & 1 \\
\hline $\mathrm{C} 14$ & & & & 0.17883 & & & & & 0.0558 & 6 \\
\hline C15 & & & & 0.08469 & & & & & 0.0264 & 12 \\
\hline $\mathrm{C} 16$ & & & & & 0.25001 & & \multirow{3}{*}{0} & \multirow{3}{*}{0} & 0.0242 & 13 \\
\hline $\mathrm{C} 17$ & & & & & 0.49999 & & & & 0.0485 & 10 \\
\hline C18 & & & & & 0.25001 & & & & 0.0243 & 14 \\
\hline C19 & & & & & & 0.30900 & \multirow{3}{*}{0.00186} & \multirow{3}{*}{0.00355} & 0.0507 & 8 \\
\hline $\mathrm{C} 20$ & & & & & & 0.58155 & & & 0.0954 & 5 \\
\hline $\mathrm{C} 21$ & & & & & & 0.10945 & & & 0.0180 & 17 \\
\hline
\end{tabular}

Concerning the ISM analysis, direct relationships among vulnerability factors (from C1 to C21) were obtained from the judgments of the experts with the question: are there any direct interrelations 
between the two factors? Figure 2 graphically presents these relationships, in which nodes represent the vulnerability factors and arrows indicate their interrelations. It is clear that 28 pairs of direct relationships exist among the factors and no bidirectional relationship exists. Only two nodes (C17 and C18) are isolated from the other nodes and node C20 has the maximum relationships. However, the indirect interrelations among the vulnerability factors and how these factors influence the rail transit system remain obscure from this picture.

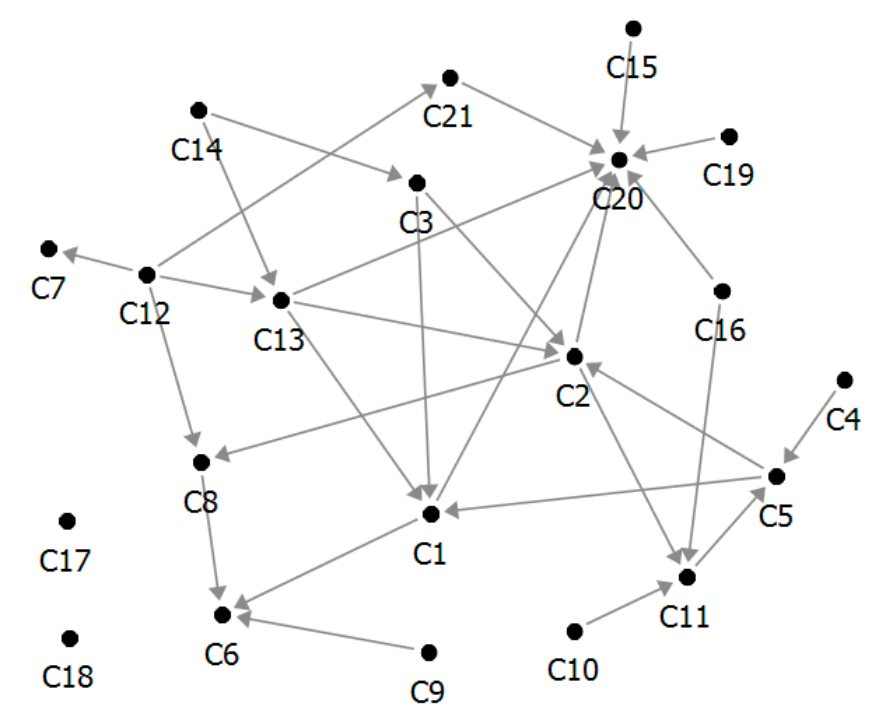

Figure 2. Relationships among vulnerability factors.

Along with Figure 2, the adjacency matrix $A$ was simultaneously generated based on the experts' judgments. The reachability matrix $M$ was then developed from the adjacency matrix with an assumption that if $i$ impacted $j$ and $j$ impacted $k$, then $i$ impacted $k$ in terms of Equation (3). The alculation process was implemented in Matlab and the final result is presented in Table 5. All of the indirect impacts were reflected in the reachability matrix as $1^{*}$ and original interrelations were expressed as 1 in Table 5.

Table 5. Reachability matrix.

\begin{tabular}{|c|c|c|c|c|c|c|c|c|c|c|c|c|c|c|c|c|c|c|c|c|c|}
\hline Factor & $C_{1}$ & $C_{2}$ & $C_{3}$ & $C_{4}$ & $C_{5}$ & $C_{6}$ & $C_{7}$ & $C_{8}$ & $C_{9}$ & $C_{10}$ & $C_{11}$ & $C_{12}$ & $C_{13}$ & $C_{14}$ & $C_{15}$ & $C_{16}$ & $C_{17}$ & $C_{18}$ & $C_{19}$ & $C_{20}$ & $C_{21}$ \\
\hline$C_{1}$ & 1 & 0 & 0 & 0 & 0 & 1 & 0 & 0 & 0 & 0 & 0 & 0 & 0 & 0 & 0 & 0 & 0 & 0 & 0 & 1 & 0 \\
\hline$C_{2}$ & $1^{*}$ & 1 & 0 & 0 & $1^{*}$ & $1^{*}$ & 0 & 1 & 0 & 0 & 1 & 0 & 0 & 0 & 0 & 0 & 0 & 0 & 0 & 1 & 0 \\
\hline$C_{3}$ & 1 & 1 & 1 & 0 & $1^{*}$ & $1^{*}$ & 0 & $1^{*}$ & 0 & 0 & $1^{*}$ & 0 & 0 & 0 & 0 & 0 & 0 & 0 & 0 & $1^{*}$ & 0 \\
\hline$C_{4}$ & $1^{*}$ & $1^{*}$ & 0 & 1 & 1 & $1^{*}$ & 0 & $1^{*}$ & 0 & 0 & $1^{*}$ & 0 & 0 & 0 & 0 & 0 & 0 & 0 & 0 & $1^{*}$ & 0 \\
\hline$C_{5}$ & 1 & 1 & 0 & 0 & 1 & $1^{*}$ & 0 & $1^{*}$ & 0 & 0 & $1^{*}$ & 0 & 0 & 0 & 0 & 0 & 0 & 0 & 0 & $1^{*}$ & 0 \\
\hline$C_{6}$ & 0 & 0 & 0 & 0 & 0 & 1 & 0 & 0 & 0 & 0 & 0 & 0 & 0 & 0 & 0 & 0 & 0 & 0 & 0 & 0 & 0 \\
\hline$C_{7}$ & 0 & 0 & 0 & 0 & 0 & 0 & 1 & 0 & 0 & 0 & 0 & 0 & 0 & 0 & 0 & 0 & 0 & 0 & 0 & 0 & 0 \\
\hline$C_{8}$ & 0 & 0 & 0 & 0 & 0 & 1 & 0 & 1 & 0 & 0 & 0 & 0 & 0 & 0 & 0 & 0 & 0 & 0 & 0 & 0 & 0 \\
\hline$C_{9}$ & 0 & 0 & 0 & 0 & 0 & 1 & 0 & 0 & 1 & 0 & 0 & 0 & 0 & 0 & 0 & 0 & 0 & 0 & 0 & 0 & 0 \\
\hline$C_{10}$ & $1^{*}$ & $1^{*}$ & 0 & 0 & $1^{*}$ & $1^{*}$ & 0 & 0 & 0 & 1 & 1 & 0 & 0 & 0 & 0 & 0 & 0 & 0 & 0 & $1^{*}$ & 0 \\
\hline$C_{11}$ & $1^{*}$ & $1^{*}$ & 0 & 0 & 1 & $1^{*}$ & 0 & 0 & 0 & 0 & 1 & 0 & 0 & 0 & 0 & 0 & 0 & 0 & 0 & $1^{*}$ & 0 \\
\hline$C_{12}$ & $1^{*}$ & $1^{*}$ & 0 & 0 & $1^{*}$ & $1^{*}$ & 1 & 1 & 0 & 0 & 0 & 1 & 1 & 0 & 0 & 0 & 0 & 0 & 0 & $1^{*}$ & 1 \\
\hline$C_{13}$ & 1 & 1 & 0 & 0 & $1^{*}$ & $1^{*}$ & 0 & $1^{*}$ & 0 & 0 & 0 & 0 & 1 & 0 & 0 & 0 & 0 & 0 & 0 & 1 & 0 \\
\hline$C_{14}$ & $1^{*}$ & $1^{*}$ & 1 & 0 & $1^{*}$ & $1^{*}$ & 0 & $1^{*}$ & 0 & 0 & 0 & 0 & 1 & 1 & 0 & 0 & 0 & 0 & 0 & $1^{*}$ & 0 \\
\hline$C_{15}$ & 0 & 0 & 0 & 0 & 0 & 0 & 0 & 0 & 0 & 0 & 0 & 0 & 0 & 0 & 1 & 0 & 0 & 0 & 0 & 1 & 0 \\
\hline$C_{16}$ & $1^{*}$ & $1^{*}$ & 0 & 0 & $1^{*}$ & $1^{*}$ & 0 & $1^{*}$ & 0 & 0 & 1 & 0 & 0 & 0 & 0 & 1 & 0 & 0 & 0 & 1 & 0 \\
\hline$C_{17}$ & 0 & 0 & 0 & 0 & 0 & 0 & 0 & 0 & 0 & 0 & 0 & 0 & 0 & 0 & 0 & 0 & 1 & 0 & 0 & 0 & 0 \\
\hline$C_{18}$ & 0 & 0 & 0 & 0 & 0 & 0 & 0 & 0 & 0 & 0 & 0 & 0 & 0 & 0 & 0 & 0 & 0 & 1 & 0 & 0 & 0 \\
\hline$C_{19}$ & 0 & 0 & 0 & 0 & 0 & 0 & 0 & 0 & 0 & 0 & 0 & 0 & 0 & 0 & 0 & 0 & 0 & 0 & 1 & 1 & 0 \\
\hline$C_{20}$ & 0 & 0 & 0 & 0 & 0 & 0 & 0 & 0 & 0 & 0 & 0 & 0 & 0 & 0 & 0 & 0 & 0 & 0 & 0 & 1 & 0 \\
\hline$C_{21}$ & 0 & 0 & 0 & 0 & 0 & 0 & 0 & 0 & 0 & 0 & 0 & 0 & 0 & 0 & 0 & 0 & 0 & 0 & 0 & 1 & 1 \\
\hline
\end{tabular}


The level partitioning of matrix $M$ was presented in Table 6 . The reachability set in the second column consisted of the factors which were shown as a 1 in each row of Table 5. The antecedent set consisted of the factors which were shown as a 1 in each column of Table 5 . The last column was the intersection set which contained the common factors in reachability and antecedent set. These factors were the elements that would be placed in the first level of the structure. In Table 6, factors C6, C7, C17, $\mathrm{C} 18$, and $\mathrm{C} 20$ were found at level 1 and subsequently removed before the next partition. The process was repeated for four times until all factors were well arranged.

Table 6. Level partition of reachability matrix.

\begin{tabular}{|c|c|c|c|}
\hline Factor & Reachability Set & Antecedent Set & Intersectionet \\
\hline \multicolumn{4}{|c|}{$L_{1}=\{\mathrm{C} 6, \mathrm{C} 7, \mathrm{C} 17, \mathrm{C} 18, \mathrm{C} 20\}$} \\
\hline $\mathrm{C} 1$ & $1,6,20$ & $1,2,3,4,5,10,11,12,13,14,16$ & 1 \\
\hline $\mathrm{C} 2$ & $1,2,5,6,8,11,20$ & $2,3,4,5,10,11,12,13,14,16$ & $2,5,11$ \\
\hline $\mathrm{C} 3$ & $1,2,3,5,6,8,11,20$ & 3,14 & 3 \\
\hline C4 & $1,2,4,5,6,8,11,20$ & 4 & 4 \\
\hline C5 & $1,2,5,6,8,11,20$ & $2,3,4,5,10,11,12,13,14,16$ & $2,5,11$ \\
\hline C6 & 6 & $1,2,3,4,5,6,8,9,10,11,12,13,14,16$ & 6 \\
\hline $\mathrm{C} 7$ & 7 & 7,12 & 7 \\
\hline $\mathrm{C} 8$ & 6,8 & $2,3,4,5,8,10,11,12,13,14,16$ & 8 \\
\hline C9 & 6,9 & 9 & 9 \\
\hline $\mathrm{C} 10$ & $1,2,5,6,8,10,11,20$ & 10 & 10 \\
\hline C11 & $1,2,5,6,8,11,20$ & $2,3,4,5,10,11,12,13,14,16$ & $2,5,11$ \\
\hline C12 & $1,2,5,6,7,8,11,12,13,20,21$ & 12 & 12 \\
\hline $\mathrm{C} 13$ & $1,2,5,6,8,11,13,20$ & $12,13,14$ & 13 \\
\hline $\mathrm{C} 14$ & $1,2,5,6,8,11,13,14,20$ & 14 & 14 \\
\hline C15 & 15,20 & 15 & 15 \\
\hline C16 & $1,2,5,6,8,11,16,20$ & 16 & 16 \\
\hline $\mathrm{C} 17$ & 17 & 17 & 17 \\
\hline $\mathrm{C} 18$ & 18 & 18 & 18 \\
\hline C19 & 19,20 & 19 & 19 \\
\hline $\mathrm{C} 20$ & 20 & $1,2,3,4,5,10,11,12,13,14,15,16,19,20,21$ & 20 \\
\hline $\mathrm{C} 21$ & 20,21 & 12,21 & 21 \\
\hline \multicolumn{4}{|c|}{$L_{2}=\{C 1, C 8, C 9, C 15, C 19, C 21\}$} \\
\hline C1 & 1 & $1,2,3,4,5,10,11,12,13,14,16$ & 1 \\
\hline $\mathrm{C} 2$ & $1,2,5,8,11$ & $2,3,4,5,10,11,12,13,14,16$ & $2,5,11$ \\
\hline $\mathrm{C} 3$ & $1,2,3,5,8,11$ & 3,14 & 3 \\
\hline $\mathrm{C} 4$ & $1,2,4,5,8,11$ & 4 & 4 \\
\hline C5 & $1,2,5,8,11$ & $2,3,4,5,10,11,12,13,14,16$ & $2,5,11$ \\
\hline $\mathrm{C} 8$ & 8 & $2,3,4,5,8,10,11,12,13,14,16$ & 8 \\
\hline C9 & 9 & 9 & 9 \\
\hline $\mathrm{C} 10$ & $1,2,5,8,10,11$ & 10 & 10 \\
\hline C11 & $1,2,5,8,11$ & $2,3,4,5,10,11,12,13,14,16$ & $2,5,11$ \\
\hline C12 & $1,2,5,8,11,12,13,21$ & 12 & 12 \\
\hline C13 & $1,2,5,8,11,13$ & $12,13,14$ & 13 \\
\hline $\mathrm{C} 14$ & $1,2,3,5,8,11,13,14$ & 14 & 14 \\
\hline C15 & 15 & 15 & 15 \\
\hline $\mathrm{C} 16$ & $1,2,5,8,11,16$ & 16 & 16 \\
\hline C19 & 19 & 19 & 19 \\
\hline $\mathrm{C} 21$ & 21 & 12,21 & 21 \\
\hline \multicolumn{4}{|c|}{$L_{3}=\{C 2, C 5, C 11\}$} \\
\hline $\mathrm{C} 2$ & $2,5,11$ & $2,3,4,5,10,11,12,13,14,16$ & $2,5,11$ \\
\hline $\mathrm{C} 3$ & $2,3,5,11$ & 3,14 & 3 \\
\hline $\mathrm{C} 4$ & $2,4,5,11$ & 4 & 4 \\
\hline $\mathrm{C} 5$ & $2,5,11$ & $2,3,4,5,10,11,12,13,14,16$ & $2,5,11$ \\
\hline $\mathrm{C} 10$ & $2,5,10,11$ & 10 & 10 \\
\hline C11 & $2,5,11$ & $2,3,4,5,10,11,12,13,14,16$ & $2,5,11$ \\
\hline
\end{tabular}


Table 6. Cont.

\begin{tabular}{cccc}
\hline Factor & Reachability Set & Antecedent Set & Intersectionet \\
\hline C12 & $2,5,11,12,13$ & 12 & 12 \\
C13 & $2,5,11,13$ & $12,13,14$ & 13 \\
C14 & $2,3,5,11,13,14$ & 14 & 14 \\
C16 & $2,5,11,16$ & 16 & 16 \\
\hline & & $L_{4}=\{C 3, C 4, C 10, C 13, C 16\}$ & 3 \\
\hline C3 & 3 & 3,14 & 4 \\
C4 & 4 & 4 & 10 \\
C10 & 10 & 10 & 12 \\
C12 & 12,13 & 12 & 13 \\
C13 & 13 & $12,13,14$ & 14 \\
C14 & $3,13,14$ & 14 & 16 \\
C16 & 16 & 16 & \\
\hline \multicolumn{5}{c}{12} & 12 & 12 & 12 \\
\hline C14 & 14 & 14 & \\
\hline
\end{tabular}

Basis on the level partition result and referring to the fifth step of ISM procedure introduced above, the interpretative structure model for the vulnerability factors was obtained, which is a five-layer hierarchy as shown in Figure 3. Several observations could be drawn from Figure 3. First, this model is not symmetric. Second, factors C17 and C18 are entirely independent and have no relationship with the other factors. The inherent properties of these factors have been reserved after the matrix operation. Third, factors C14 and C12 are at the deepest layer of the structure. Factors C6, C7, C17, C18 and C20 are at the surface layer of the structure. The rest of the factors are in the middle. The second level has the maximum number of factors (6): $\mathrm{C} 1, \mathrm{C} 8, \mathrm{C} 9, \mathrm{C} 18, \mathrm{C} 19$ and $\mathrm{C} 21$. Furthermore, factors $\mathrm{C} 2, \mathrm{C} 5$ and $\mathrm{C} 11$ have bidirectional relationships which cannot be perceived easily in Figure 2.

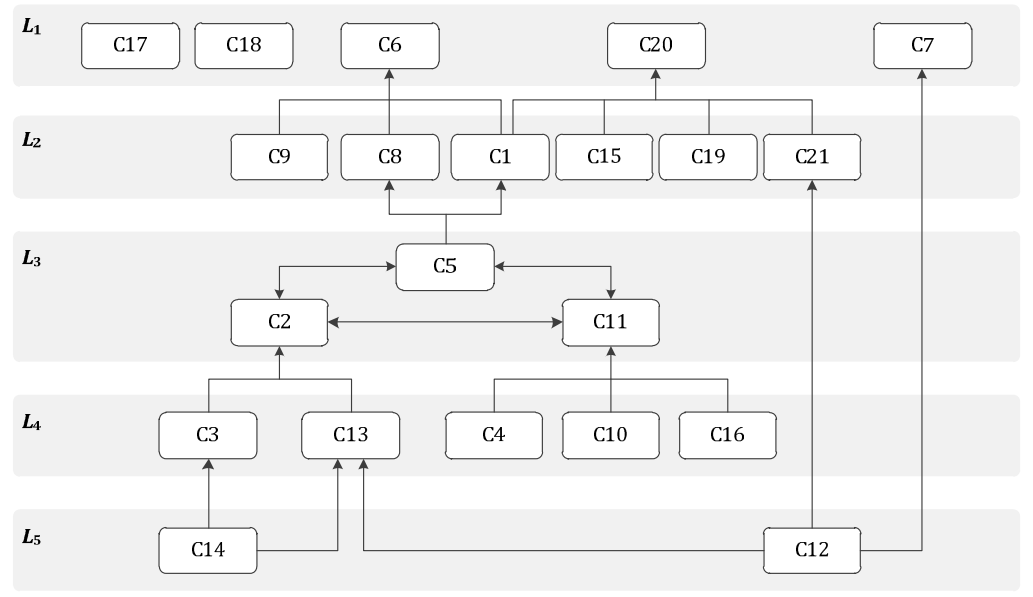

Figure 3. Interpretative structural model.

\section{Discussion}

Knowing what vulnerability factors influence and how these factors influence the operation of urban rail transit system is a worthy work for promoting the operational safety level. With the assistance of the expert elicitation and the application of an integrated AHP-ISM method, this study conducted a comprehensive exploration on the vulnerability factors, in which the importance weights of each factor are obtained and the influence paths of each factor are elaborated in a more evident way. Regarding the weights of vulnerability factors, a more visualized presentation about the importance value of each factor can be seen in Figure 4. Consistent with the current studies 
concerning the rail transit safety operation [28,29], the management dimension (B4), is believed to be of greatest importance in the criteria level. Not only can more scientific and comprehensive management lower the probability of accidents, but it can also limit the loss associated with those accidents [1]. With the highest weight in the criteria level, the factors under the management dimension show the relative high importance in the sub-criteria level. Education and training (C13), safety investment (C12), rules and regulations (C14), and organizational structure (C15) rank 1st, 2nd, 6th and 12th, respectively. Obviously, only with sufficient education and training can employees make their work more efficient and handle unexpected situation more flexibly. While adequate safety investment is the most important way to guarantee a safe operating environment [40]. Individual dimension (B1) plays the second importance role in the safety operation of urban rail transit system. Related factors, involving individual technical capabilities (C1) and security awareness (C2), also obtain the higher weights in the sub-criteria level. As the fundamental determinants of human performance, these factors are also critical because positive human performance is essential to keep the system safe running in normal circumstance and bring the abnormal operation back to normal one [3,4]. Moreover, it is well worthy of attention that the topology of the network (C17) and the equipment/facility interdependency (C18) occupy the middle positions in the sub-criteria level, which is suggestive of the relative importance of these two factors. Nevertheless, they have not been mentioned in previous studies related to risk analysis of urban rail transit system [26,27].

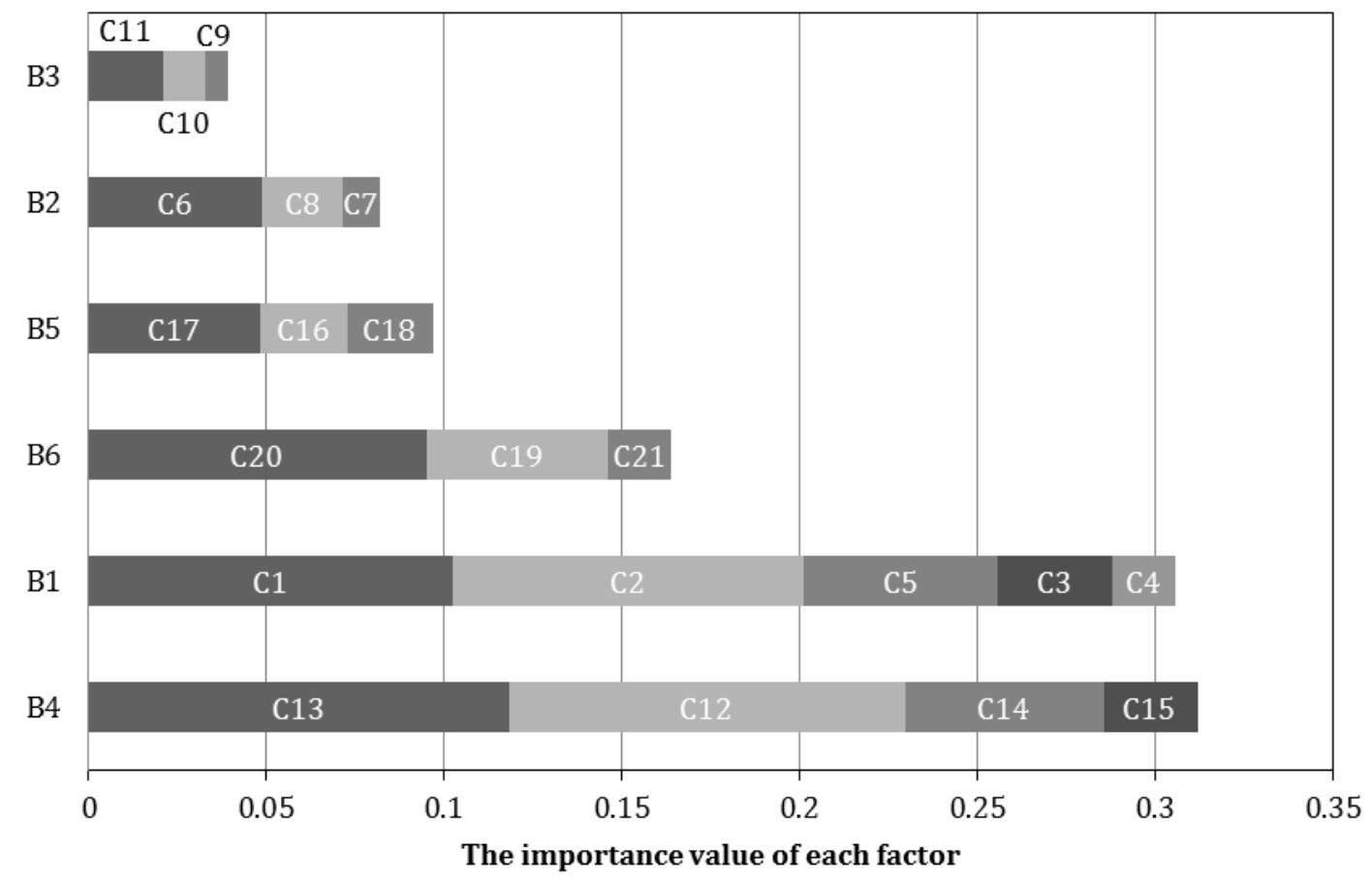

Figure 4. The importance value of each factor.

Concerning the interpretative structural model for vulnerability factors, Figure 5 depicts the five-layer hierarchical structure with consideration of the importance weight of each factor, in which different dimension factors are filled with different color. The higher weight the dimension possess, the darker the fill color is. In Figure 5, it can be intuitively seen that the fill color of vulnerability factors become darker as they move to the deeper layer. The vulnerability factors belonging to the same dimension are inclined to gather and have more interactions, which conform to reality. In addition, the majority of management factors such as regulations and rules (C14) and safety investment (C12) are at the deepest hierarchy of the mode, meaning these factors contribute significantly latent impacts on other dimension factors. It is generally recognized that the improper regulation system and the 
insufficient safety investment is the immediate cause of the accidents [42]. The intangible factors are significant contributors to the safety operation of rail transit system [30]. Consequently, more attention should be paid to these factors. In addition, individual security awareness (C2), individual physical and physiological state (C5), and operational environment (C11) form a circle in the structure. A pleasant operational environment could make staff and passengers feel comfortable [26]. In such comfortable environment, individuals could keep favorable physical and physiological states which had positive effects on individuals' security awareness [30]. With the high level of security awareness, potentially dangerous actions or factors could be prevented or handled in time, which would, in turn, guarantee offering a safe and comfortable environment. Although network topology (C17) and equipment/facility interdependency (C18) are isolated from other vulnerability factors and have no impacts on the rest, they should be considered in establishing the preventive actions. There is a general consensus that different topological structures of rail transit systems have different degrees of vulnerability from disruptions [31], and the interdependency between the equipment in the system increase vulnerability [16].

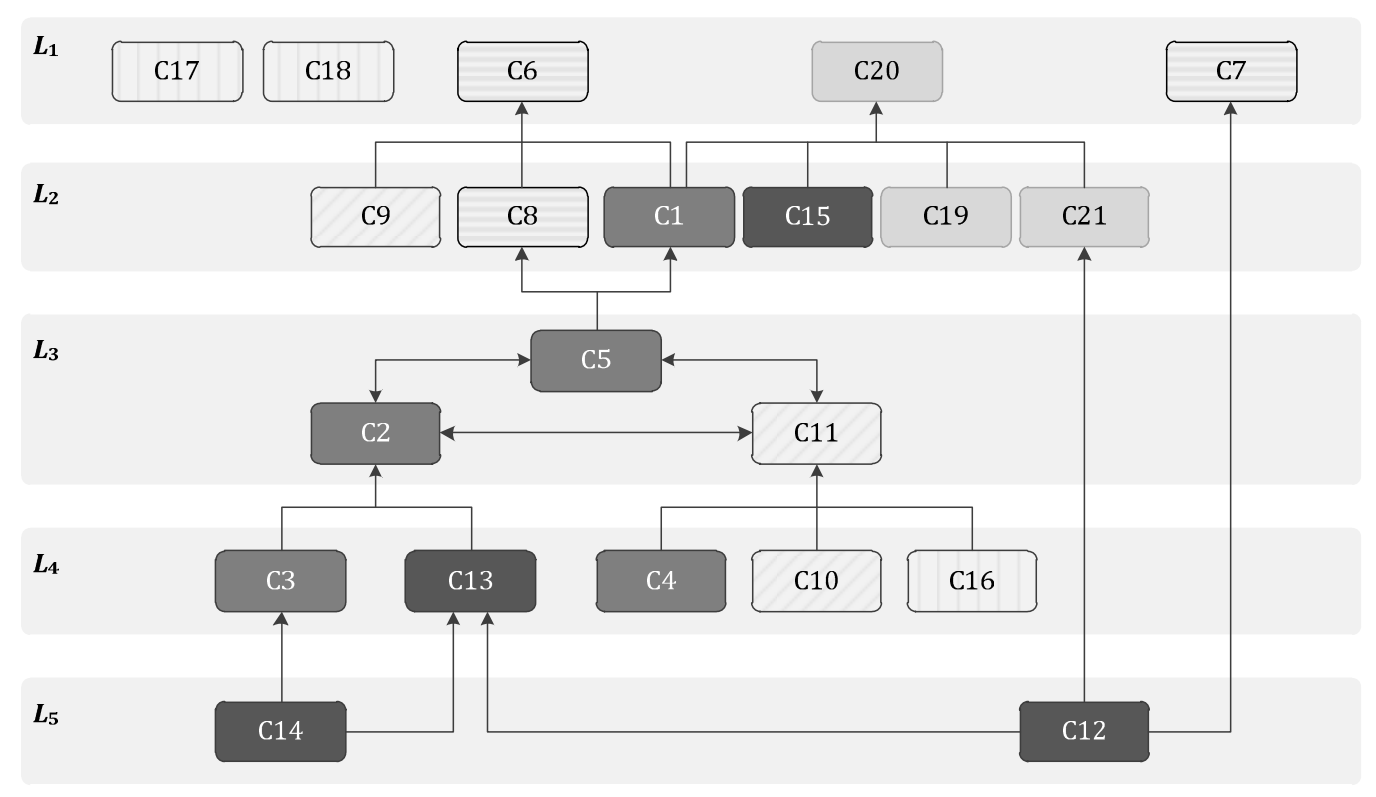

Figure 5. Interpretative structural model with the importance of each factor.

Comparing to the conventional safety analysis, exploring the vulnerability factors allows for the production of new perception into elevating system safety of urban rail transit operation. As for the foundation of this study, the extracted vulnerability factors may not be exhaustive. In this paper, the vulnerability factors were further reviewed by five professors. All professors were experienced experts who were occupied in safety related studies for more than ten years. For such reason, it can be reasonably argued that the current list contains the majority of the vulnerability factors that influence system performance and the extraction process could be regarded to possess superior credibility. With regard to the integrated method proposed in this paper, expert elicitation was employed to obtain the primary data. In fact, expert elicitation depends heavily on the participants' experience and knowledge, and their information about the investigate topic. Adopting this technique would make the result more subjective. How to quantify the contributions of vulnerability factors in a more objective way will be a priority in further research.

\section{Conclusions}

Safety is one of the crucial considerations for the residents to travel by urban rail transit system, other than speed and flexibility. Understanding the inherent property of rail transit vulnerability 
is conductive to retain a high level of safety. Starting from the definition of vulnerability, this paper shows how the application of an AHP-ISM based integrated method can lead to a better understand how various vulnerability factors influence the operation of the rail transit system. Based on the inputs from a thorough literature review, a list involving 21 vulnerability factors is generated. With the assistance of the expert elicitation technique, the fundamental data for further analysis are obtained from nine experienced experts. The importance weights of vulnerability factors are quantified and the interrelations among them are illustrated by utilizing the proposed integrated method. The management factors, such as safety investments, rules and regulations are extraordinarily crucial because these factors not only occupy relative importance weights but also locate at the bottom level of the interpretative structural model. It is also concluded that network topology and equipment/facility interdependency are critical factors which have largely been ignored in previous studies. More emphases should be placed on these abovementioned factors and corresponding strategies and measures should be formulated by which the operation of urban rail transit system could be safer and more reliable. The research findings provide valuable insights into the perception of and knowledge about safety operation of urban rail transit system. For the sake of simplicity, the weights of factors are ascertained through AHP method, and it is encouraged to apply ANP method to analyze the vulnerability factors in future research.

Acknowledgments: This work was supported by the National Natural Science Foundation of China (Grant No. 51578144). The authors would like to acknowledge the experts who participated in the study and those who provided suggestions.

Author Contributions: The authors Liangliang Song and Qiming Li drafted the manuscript, George F. List contributed to research methodology and polished the language, Yongliang Deng assisted in literature review and data analysis, Ping Lu assisted in data collection. All authors have read and approved the final version of the manuscript.

Conflicts of Interest: The authors declare no conflict of interest.

\section{References}

1. Li, Q.M.; Song, L.L.; List, G.; Deng, Y.L.; Zhou, Z.P.; Liu, P. A new approach to understand metro operation safety by exploring metro operation hazard network (mohn). Saf. Sci. 2017, 93, 50-61. [CrossRef]

2. National Bureau of Statistic of China. 2016. Available online: http://www.stats.gov.cn/english/ Statisticaldata/AnnualData (accessed on 15 May 2017).

3. Kyriakidis, M.; Majumdar, A.; Grote, G.; Ochieng, W. Development and assessment of taxonomy for performance-shaping factors for railway operations. Transp. Res. Rec. 2012, 2289, 145-153. [CrossRef]

4. Kyriakidis, M.; Majumdar, A.; Ochieng, W.Y. Data based framework to identify the most significant performance shaping factors in railway operations. Saf. Sci. 2015, 78, 60-76. [CrossRef]

5. Song, X.M.; Li, C.Y. Subway Station Operational Safety Analysis Method Based on Spatial and Temporal Resource Analysis. In Proceedings of the CICTP 2014: Safe, Smart, and Sustainable Multimodal Transportation Systems, Changsha, China, 4-7 July 2014; pp. 2660-2665.

6. Rausand, M. Risk Assessment: Theory, Methods, and Applications; John Wiley \& Sons: Hoboken, NJ, USA, 2011.

7. Lou, Y.Y.; Zhang, L.H. Defending transportation networks against random and targeted attacks. Transp. Res. Rec. 2011, 2234, 31-40. [CrossRef]

8. Lownes, N.E.; Wang, Q.X.; Ibrahim, S.; Ammar, R.A.; Rajasekaran, S.; Sharma, D. Many-to-many game-theoretic approach for the measurement of transportation network vulnerability. Transp. Res. Rec. 2011, 2263, 1-8. [CrossRef]

9. Deng, Y.L.; Li, Q.M.; Lu, Y. A research on subway physical vulnerability based on network theory and fmeca. Saf. Sci. 2015, 80, 127-134. [CrossRef]

10. Wan, X.; Li, Q.M.; Yuan, J.F.; Schonfeld, P.M. Metro passenger behaviors and their relations to metro incident involvement. Accid. Anal. Prev. 2015, 82, 90-100. [CrossRef] [PubMed]

11. Zimmerman, R. Mass transit infrastructure and urban health. J. Urban Health 2005, 82, 21-32. [CrossRef] [PubMed] 
12. Sun, D.; Zhao, Y.; Lu, Q.C. Vulnerability analysis of urban rail transit networks: A case study of shanghai, china. Sustainability 2015, 7, 6919. [CrossRef]

13. Albert, R.; Albert, I.; Nakarado, G.L. Structural vulnerability of the north american power grid. Phys. Rev. E 2004, 69. [CrossRef] [PubMed]

14. Kamara, S.; Fahmy, S.; Schultz, E.; Kerschbaum, F.; Frantzen, M. Analysis of vulnerabilities in internet firewalls. Comput. Secur. 2003, 22, 214-232. [CrossRef]

15. Srinivasan, K. Transportation Network Vulnerability Assessment: A Quantitative Framework; Transportation Security Papers 2002; Southeastern Transportation Center: Knoxville, TN, USA, 2002; pp. 63-82.

16. Grubesic, T.H.; Matisziw, T.C. A typological framework for categorizing infrastructure vulnerability. GeoJournal 2013, 78, 287-301. [CrossRef]

17. Berdica, K. An introduction to road vulnerability: What has been done, is done and should be done. Transp. Policy 2002, 9, 117-127. [CrossRef]

18. Erath, A.; Birdsall, J.; Axhausen, K.W.; Hajdin, R. Vulnerability assessment methodology for swiss road network. Transp. Res. Rec. 2009, 2137, 118-126. [CrossRef]

19. Haimes, Y.Y. On the definition of vulnerabilities in measuring risks to infrastructures. Risk Anal. 2006, 26, 293-296. [CrossRef] [PubMed]

20. Johansson, J.; Hassel, H. An approach for modelling interdependent infrastructures in the context of vulnerability analysis. Reliab. Eng. Syst. Saf. 2010, 95, 1335-1344. [CrossRef]

21. Tampere, C.M.J.; Stada, J.; Immers, B.; Peetermans, E.; Organe, K. Methodology for identifying vulnerable network sections in a national road. Transp. Res. Rec. 2007, 2012, 1-10. [CrossRef]

22. Apostolakis, G.E.; Lemon, D.M. A screening methodology for the identification and ranking of infrastructure vulnerabilities due to terrorism. Risk Anal. 2005, 25, 361-376. [CrossRef] [PubMed]

23. Aven, T. A unified framework for risk and vulnerability analysis covering both safety and security. Reliab. Eng. Syst. Saf. 2007, 92, 745-754. [CrossRef]

24. Schuchmann, G. Road network vulnerability-evaluation of measures in ranking damages and developments. Period Polytech. Civ. Eng. 2010, 54, 61-65. [CrossRef]

25. Johansson, J.; Hassel, H.; Zio, E. Reliability and vulnerability analyses of critical infrastructures: Comparing two approaches in the context of power systems. Reliab. Eng. Syst. Saf. 2013, 120, 27-38. [CrossRef]

26. Lu, Y.; Li, Q.; Song, L. Safety risk analysis on subway operation based on socio-technical systems. In Proceedings of the 2012 International Conference on Quality, Reliability, Risk, Maintenance, and Safety Engineering (ICQR2MSE), Chengdu, China, 15-18 June 2012; pp. 180-184.

27. Lu, Y.; Li, Q.; Xiao, W. Case-based reasoning for automated safety risk analysis on subway operation: Case representation and retrieval. Saf. Sci. 2013, 57, 75-81. [CrossRef]

28. Kyriakidis, M.; Hirsch, R.; Majumdar, A. Metro railway safety: An analysis of accident precursors. Saf. Sci. 2012, 50, 1535-1548. [CrossRef]

29. Gershon, R.R.M.; Qureshi, K.A.; Barrera, M.A.; Erwin, M.J.; Goldsmith, F. Health and safety hazards associated with subways: A review. J. Urban Health 2005, 82, 10-20. [CrossRef] [PubMed]

30. Song, L.L.; Li, Q.M.; Lu, Y.; Deng, Y.F. Research on factors affecting vulnerability of subway system. China Saf. Sci. J. 2016, 26, 64-69.

31. Derrible, S.; Kennedy, C. Network analysis of world subway systems using updated graph theory. Transp. Res. Rec. 2009, 2112, 17-25. [CrossRef]

32. Derrible, S.; Kennedy, C. Evaluating, comparing, and improving metro networks application to plans for toronto, canada. Transp. Res. Rec. 2010, 2146, 43-51. [CrossRef]

33. Pederson, P.; Dudenhoeffer, D.; Hartley, S.; Permann, M. Critical Infrastructure Interdependency Modeling: A Survey of Us and International Research; Technical Report INL/EXT-06-11464; Idaho National Laboratory: Idaho Falls, ID, USA, 2006.

34. Khalil, N.; Kamaruzzaman, S.N.; Baharum, M.R. Ranking the indicators of building performance and the users' risk via analytical hierarchy process (ahp): Case of malaysia. Ecol. Indic. 2016, 71, 567-576. [CrossRef]

35. Mohanty, M.; Shankar, R. Modelling uncertainty in sustainable integrated logistics using fuzzy-tism. Transp. Res. Part D 2017, 53, 471-491. [CrossRef]

36. Saaty, T.L. The modern science of multicriteria decision making and its practical applications: The ahp/anp approach. Oper. Res. 2013, 61, 1101-1118. [CrossRef] 
37. Warfield, J.N. Toward interpretation of complex structural models. IEEE Trans. Syst. Man Cybern. 1974, 4, 405-417. [CrossRef]

38. Bolger, F.; Rowe, G. The aggregation of expert judgment: Do good things come to those who weight? Risk Anal. 2015, 35, 5-11. [CrossRef] [PubMed]

39. Morgan, M.G. Use (and abuse) of expert elicitation in support of decision making for public policy. Proc. Natl. Acad. Sci. USA 2014, 111, 7176-7184. [CrossRef] [PubMed]

40. Zhang, G.; Thai, V.V. Expert elicitation and bayesian network modeling for shipping accidents: A literature review. Saf. Sci. 2016, 87, 53-62. [CrossRef]

41. Maniram Kumar, A.; Rajakarunakaran, S.; Arumuga Prabhu, V. Application of fuzzy heart and expert elicitation for quantifying human error probabilities in lpg refuelling station. J. Loss Prev. Process Ind. 2017, 48, 186-198. [CrossRef]

42. Ma, Y.; Zhao, Q.; Xi, M. Decision-makings in safety investment: An opportunity cost perspective. Saf. Sci. 2016, 83, 31-39. [CrossRef]

(C) 2017 by the authors. Licensee MDPI, Basel, Switzerland. This article is an open access article distributed under the terms and conditions of the Creative Commons Attribution (CC BY) license (http:// creativecommons.org/licenses/by/4.0/). 